\title{
Systematic review of the role of indocyanine green near-infrared fluorescence in safe laparoscopic cholecystectomy (Review)
}

\author{
DRAGOS SERBAN ${ }^{1,2}$, DUMITRU CRISTINEL BADIU ${ }^{1,3}$, DRAGOS DAVITOIU $^{1,4}$, CIPRIAN TANASESCU $^{5}$, \\ MIHAIL SILVIU TUDOSIE ${ }^{6,7}$, ALEXANDRU DAN SABAU ${ }^{5}$, ANA MARIA DASCALU $^{1 *}$, CORNELIU TUDOR $^{2}$, \\ SIMONA ANDREEA BALASESCU ${ }^{2}$, BOGDAN SOCEA ${ }^{1,8}$, DANIEL OVIDIU COSTEA ${ }^{9,10}$, ANCA ZGURA ${ }^{11,12}$, \\ ANDREEA CRISTINA COSTEA ${ }^{13}$, LAURA CARINA TRIBUS ${ }^{14,15}$ and CATALIN GABRIEL SMARANDACHE ${ }^{1,2}$ \\ ${ }^{1}$ Department of General Surgery, Faculty of Medicine, 'Carol Davila' University of Medicine and Pharmacy, \\ 020021 Bucharest; ${ }^{2}$ Fourth Department of Surgery, Emergency University Hospital, 050098 Bucharest; \\ ${ }^{3}$ Department of General Surgery, 'Bagdasar Arseni’ Emergency Clinical Hospital, 041915 Bucharest; \\ ${ }^{4}$ First Department of General Surgery, Emergency University Hospital, 050098 Bucharest; ${ }^{5}$ Third Clinical Department, \\ Faculty of Medicine, 'Lucian Blaga' University of Sibiu, 550169 Sibiu; ${ }^{6}$ Discipline of Clinical Toxicology, \\ Faculty of Medicine, 'Carol Davila' University of Medicine and Pharmacy, 020021 Bucharest; ${ }^{7}$ ICU II Toxicology, \\ Clinical Emergency Hospital, 014461 Bucharest; ${ }^{8}$ Department of Surgery, 'Sf. Pantelimon' Emergency Hospital, \\ 021659 Bucharest; ${ }^{9}$ Department of Clinical Surgical Disciplines I, Faculty of Medicine, Ovidius University, \\ 900527 Constanta; ${ }^{10}$ First General Surgery Department, Emergency County Hospital, 900591 Constanta; \\ ${ }^{11}$ Department of Radiology, Oncology, and Hematology, Faculty of Medicine, 'Carol Davila' University of Medicine \\ and Pharmacy, 020011 Bucharest; ${ }^{12}$ Department of Oncology Radiotherapy, Institute of Oncology \\ 'Prof. Dr. Alexandru Trestioreanu', 022328 Bucharest; ${ }^{13}$ Department of Nephrology and Dialysis, \\ 'Diaverum' Clinic, 900612 Constanta; ${ }^{14}$ Department of Internal Medicine Gastroenterology, \\ Faculty of Medicine, 'Carol Davila' University of Medicine and Pharmacy, 020011 Bucharest; \\ ${ }^{15}$ Department of Gastroenterology, Emergency University Hospital, 050098 Bucharest, Romania
}

Received August 31, 2021; Accepted September 30, 2021

DOI: $10.3892 /$ etm.2021.11110

\begin{abstract}
With the widespread introduction of laparoscopic cholecystectomy, the incidence of iatrogenic main bile duct lesions has significantly increased, with incidences ranging from 0.2 to $1.5 \%$ according to current studies. Although there are studies regarding the use of indocyanine green (ICG) for improved visualization of the biliary anatomy, there is no consensus on the dose, timing and optimal mode of administration, or the indications in which ICG provides a real benefit through increased safety in laparoscopic cholecystectomy (LC). A systematic review was performed on articles in
\end{abstract}

Correspondence to: Dr Dumitru Cristinel Badiu, Department of General Surgery, Faculty of Medicine, 'Carol Davila' University of Medicine and Pharmacy, 37 Dionisie Lupu Street, 020021 Bucharest, Romania

E-mail: dumitru.badiu@umfcd.ro

${ }^{*}$ Contributed equally

Key words: laparoscopic cholecystectomy, indocyanine green, near-infrared fluorescence, main bile duct injuries, safe surgery, biliary anatomy
English published until March 2021, which were identified on PubMed, Springer Nature, Elsevier and Scopus via specific mesh terms: 'Indocyanine green'/'near-infrared fluorescence' and 'laparoscopic cholecystitis'. The most used method of administration of ICG was intravenously, only one study evaluated the efficiency of a near-infrared cholangiogram (NIRC) when ICG was administered directly in the gallbladder. The majority of the studies included in the review used $2.5 \mathrm{mg}$ of ICG administered within $1 \mathrm{~h}$ before imaging. The intensity of the NIRC fluorescence signal was revealed to depend on several factors, with obesity and inflammation as the most clinically significant. NIRC was reported to be a simple, feasible, safe and cost-effective procedure, which may improve safety in difficult cases of LC. NIRC use in combination with white light has been demonstrated to be superior to white light alone in identifying extrahepatic biliary anatomy, thus decreasing the risk of intraoperative bile duct injuries (BDI). For its large-scale use, data on a higher number of patients to confirm its clinical value and specific indications is required.

\section{Contents}

1. Introduction

2. Data and methods

3. Dose, timing and administration 
4. Factors influencing the intensity of the fluorescence signal and visibility of the extrahepatic biliary structures

5. Indocyanine green (ICG) near-infrared cholangiogram (NIRC) and the rate of bile duct injuries (BDI) and conversion in the study groups

6. Challenges in laparoscopic cholecystectomy (LC) using ICG near-infrared fluorescence (NIR)

7. Conclusions

\section{Introduction}

With the widespread introduction of laparoscopic cholecystectomy (LC), the incidence of iatrogenic main bile duct lesions has significantly increased, with incidences ranging from 0.2 to $1.5 \%$ according to previous studies (1-3). Although on a declining trend, with the implementation of critical view of safety (CVS) in the dissection of the elements that define Calot's triangle, bile duct injuries (BDI) remain a major concern during LC. They are a potentially life-threatening complication and one of the most frequent causes of postoperative morbidity, associated with increased hospital stay, health-associated costs, reinterventions or additional procedures for treatment. They are also one of the main causes of allegations of malpractice in biliary surgery. The main risk factors for BDI are the severity of the inflammatory process in acute cholecystitis (AC), fibro-sclerosing remodeling associated with chronic inflammation, and the anatomical variability of the bile duct, which are also risk factors for conversion to open surgery (4). Postoperative adhesions are the leading cause of conversion from laparoscopy to laparotomy (5). Thus, clinical trials reveal that, although recommended in current practice protocols, many surgeons prefer to delay LC in AC until remission of local inflammatory phenomena to avoid iatrogenic damage to the main bile duct $(6,7)$.

New safe LC surgery protocols pay special attention to the prevention of main bile duct lesions $(1,2)$, and ICG-assisted near-infrared cholangiogram (NIRC) is an emerging technique that may increase the visualization of the extra biliary structures (3). Accurate techniques, understanding of the local anatomy and adequate exposure of the extra hepatic biliary structures are key factors in preventing such injuries and providing safe LC.

Intraoperative cholangiography (IOC) provides important benefits in situations of difficult dissection or suspicion of main bile duct stones, but has a number of disadvantages including prolonging surgery, requiring portable radiology equipment, specialized personnel, irradiation, and increased costs. Routine IOC may help identify a BDI at the time of surgery but not necessarily prevent its occurrence (7). Moreover, by requiring the injection of contrast material into the bile duct, IOC may increase the risk of BDI.

Ishizawa et al first demonstrated in 2009 the usefulness of ICG NIRC in liver transplantation, by direct injection into the bile duct and in open cholecystectomy, by intravenous preoperative administration (8). This new approach was extremely attractive, particularly in the context in which the new laparoscopic systems have incorporated the software function that allows the acquisition of the image in NIR and the overlap of information over the image obtained in white light. This allows the obtaining of additional information without increasing the operating time or changing the operating time sequence (9).

ICG is a dye currently used in various medical and surgical specialties (cardiology, ophthalmology and abdominal surgery) that binds with circulating albumins and lipoproteins and is excreted into the bile almost unaltered following hepatic extraction. Its half time in the blood stream is between 3 and 5 min (10). An alternative in biliary surgery is its direct injection into the gallbladder. The molecule of ICG has an emission with a spectrum peak at $810-830 \mathrm{~nm}$, in NIR, that conveniently avoids the endogenous interferences with water and body proteins. It has an excellent safety profile for human use; however, it is crystallized using iodized salts which renders it contraindicated in patients with iodine allergies (10).

Thus far, given the novelty of the method and the relatively limited access to laparoscopic equipment with an image acquisition system for NIR, there is no consensus on the dose, timing and optimal mode of administration, or the indications in which NIRC with ICG provides a real benefit through increased safety in LC.

\section{Data and methods}

A systematic review was performed on articles in English published until March 2021, which were identified on PubMed, Springer Nature, Elsevier and Scopus via specific mesh terms: 'Indocyanine green'/'near-infrared fluorescence' and 'laparoscopic cholecystitis'. Criteria for inclusion in this systematic review were observational studies with non-malignant pathologies of gallbladder undergoing laparoscopic cholecystitis using ICG NIRC reporting at least one of the following outcomes: operative time, biliary anatomy identification time, success rate of biliary tract imaging, bile duct lesions, conversion to open surgery, hospital stay, and postoperative complications.

Exclusion criteria included malignancies, studies with no adequately described surgical procedure, studies evaluating ICG in open cholecystectomies or other hepato-biliary surgeries. Editorials, reviews, case-reports, commentaries, letters and book chapters were not included.

The systematic review analyzed information regarding: i) dose, timing and administration of ICG for NIRC used in the previously published studies; ii) the percentage in increased visualization of extrahepatic biliary structures; iii) the incidence of main bile duct lesions and conversions in the NIR-assisted group (vs. the control group, if any); and iv) secondary reactions associated with ICG administration.

All studies were categorized based on The Oxford Centre for Evidence-based Medicine, and two reviewers analyzed the abstracts for inclusion in the systematic review. A PRISMA flow chart was employed to screen studies for eligibility.

Our search resulted in 105 articles identified on PubMed, and an additional 91 in other databases (Springer Nature, Elsevier, Scopus). After duplication removal and screening for eligibility, a total of 19 clinical studies regarding the use of ICG in LC and/or robotic cholecystectomy (RC), were included in this review. A PRISMA flow diagram is revealed in Fig. 1.

The ensuing comments are based on the analysis of 19 studies (6,10-27) documenting the use of ICG NIRC in LCs or RCs, for non-malignant gallbladder disease (symptomatic 
PRISMA 2009 flow diagram
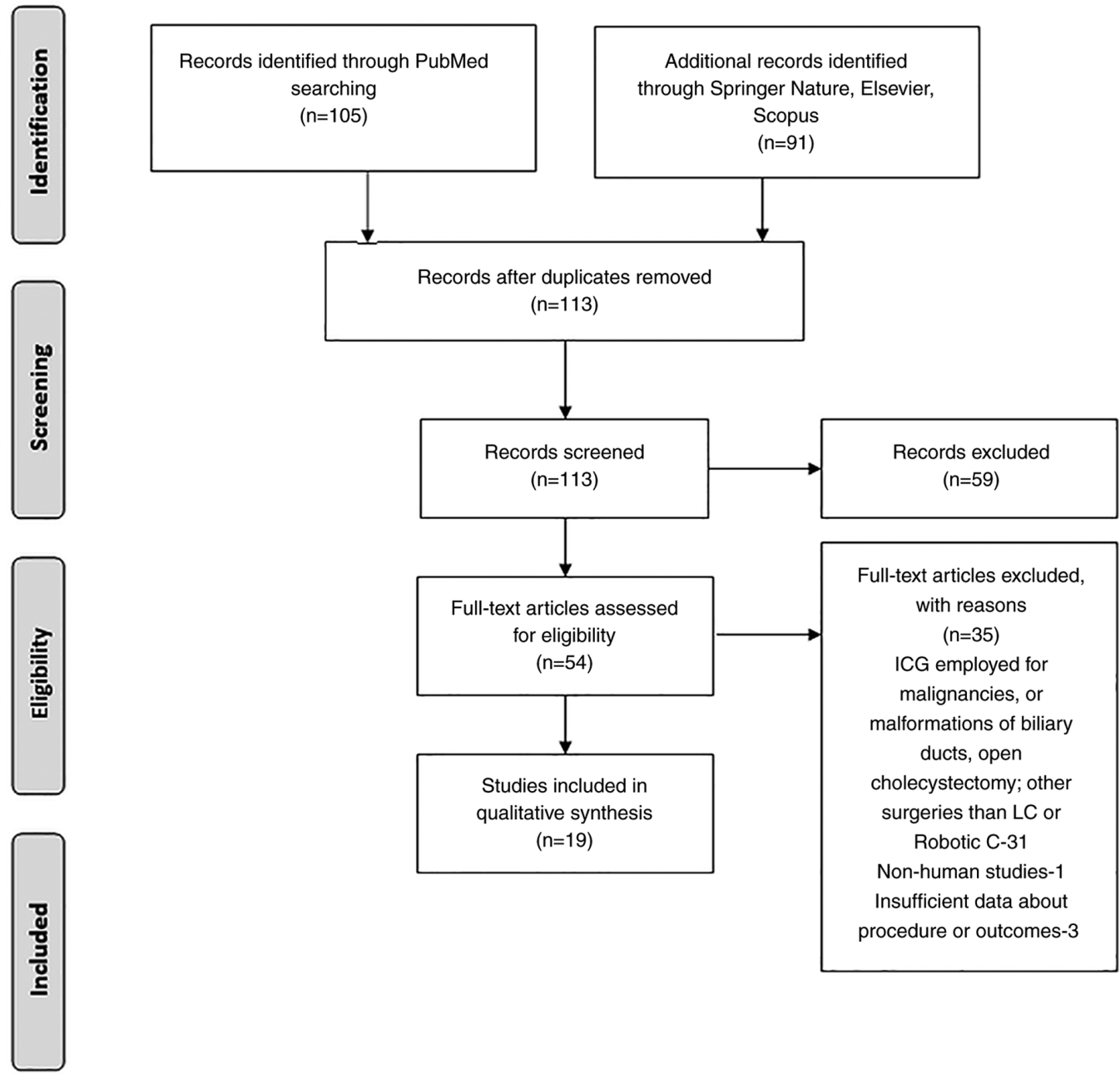

Figure 1. PRISMA flowchart of the studies included in the review.

biliary lithiasis, acute or chronic cholecystitis, and gallbladder polyps) in a total of 2,490 patients. Only 2are randomized controlled studies (RCT), 11 prospective and 6 are retrospective studies $(7,11-28)$ (Table I). The safety of the ICG was excellent, there was only one report of a self-resolved rash $(0.04 \%)$, with no other adverse reactions.

The gallbladder pathology which required LC or RC, was in most cases chronic, and was performed as elective cholecystectomy. Only two studies evaluated the role of ICG NIRC in AC and complicated cholecystitis. The degree of local inflammation is an important source of bias when analyzing the results, due to diminished visualization of the elements of the Calot's triangle.

As final outcomes, certain studies focused on the assessment of the visibility rate of the extrahepatic biliary structures, while others focused on the clinical results concerning the rate of BDI and the rate of conversion or both.

\section{Dose, timing and administration}

NIRC has been reported as a simple, feasible, safe and cost-effective procedure, which may improve safety in difficult cases of LC $(7,8)$. Its use in combination with white light has been demonstrated to be superior to white light alone in identifying extrahepatic biliary anatomy, Calot's triangle, anatomical variations, accessory hepatic ducts, thus decreasing the risk of intraoperative BDI $(11,16,17)$.

The most used method of administration of ICG was intravenously, and only one study (13) evaluated the efficiency of NIRC when ICG was administered directly into the gallbladder, either via a preexisting catheter after percutaneous gallbladder evacuation, or by direct puncture of the gallbladder intraoperatively. In order to avoid spillage, a pouch was previously created to seal the orifice. The images obtained by Liu et al were qualified to be of good quality, ensuring an adequate view of the structure during dissection, with no cases of conversion and BDI. However, in 5 cases $(10.86 \%)$ the authors reported leakage of the dye at the level of the gallbladder puncture, which impaired vision (13).

In most of the cases, ICG was administered shortly before or at the induction of anesthesia, with a time range of 30-60 min to the intervention. The doses in these cases were either a fixed dose varying between $1.25-7.5 \mathrm{mg}$ of diluted ICG solution (14-24,27), or an adjusted dose of $0.02-0.62 \mathrm{mg} / \mathrm{kg}(11,12,28)$. The majority of the studies included in the review used $2.5 \mathrm{mg}$ administered within $1 \mathrm{~h}$ before imaging (7,14-23). A supplemental bolus was used intraoperatively in selected cases, to improve observation 


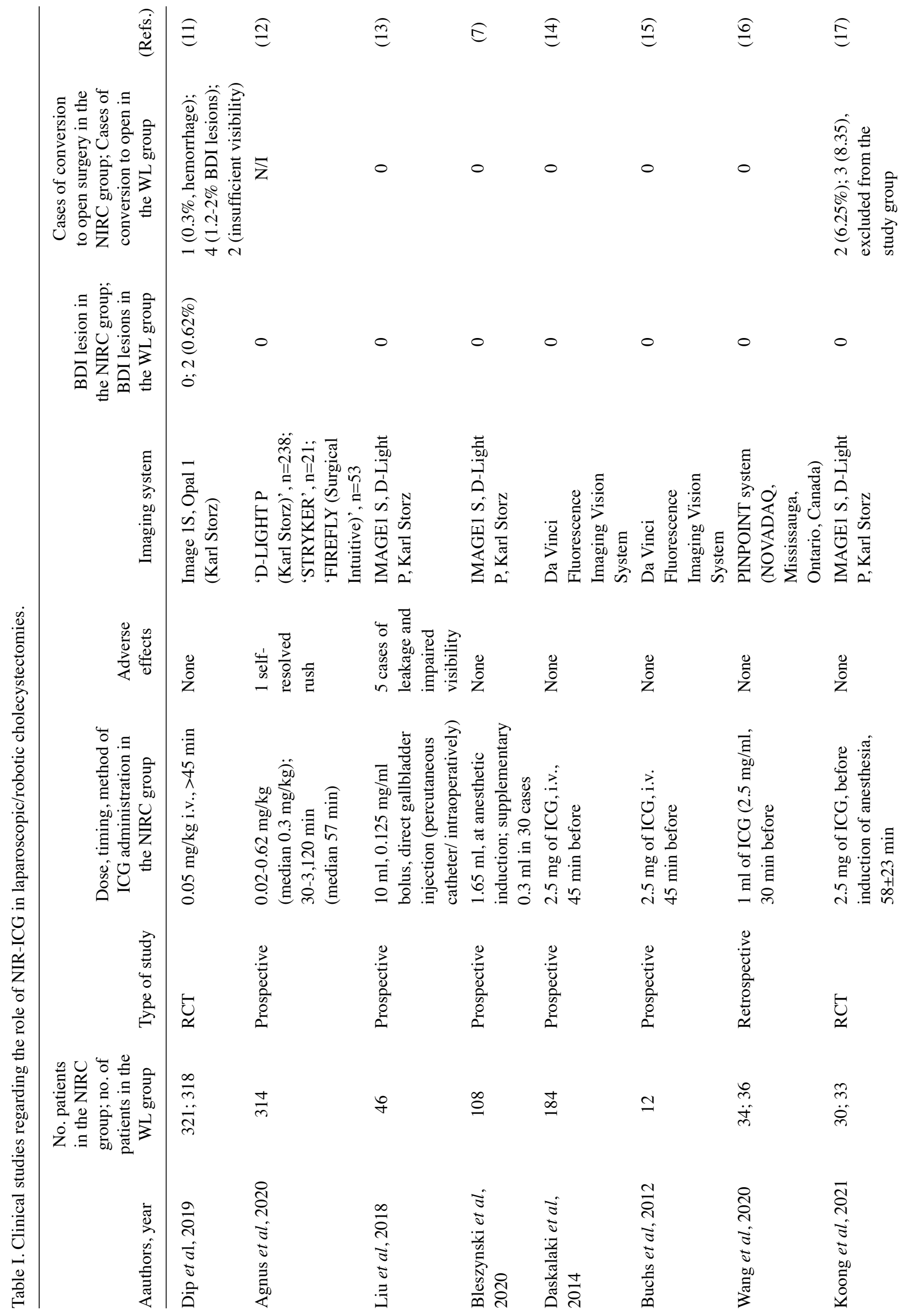




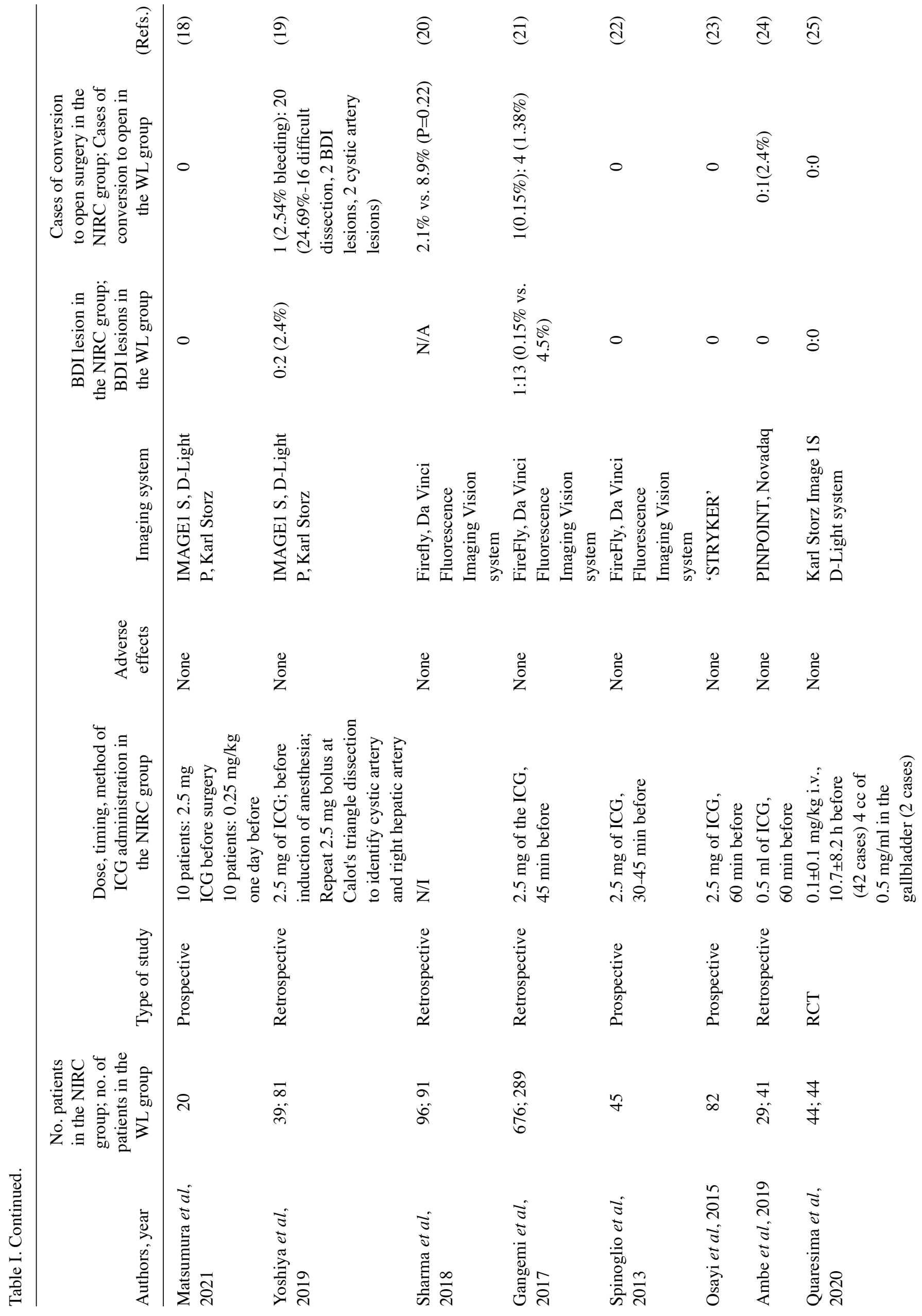




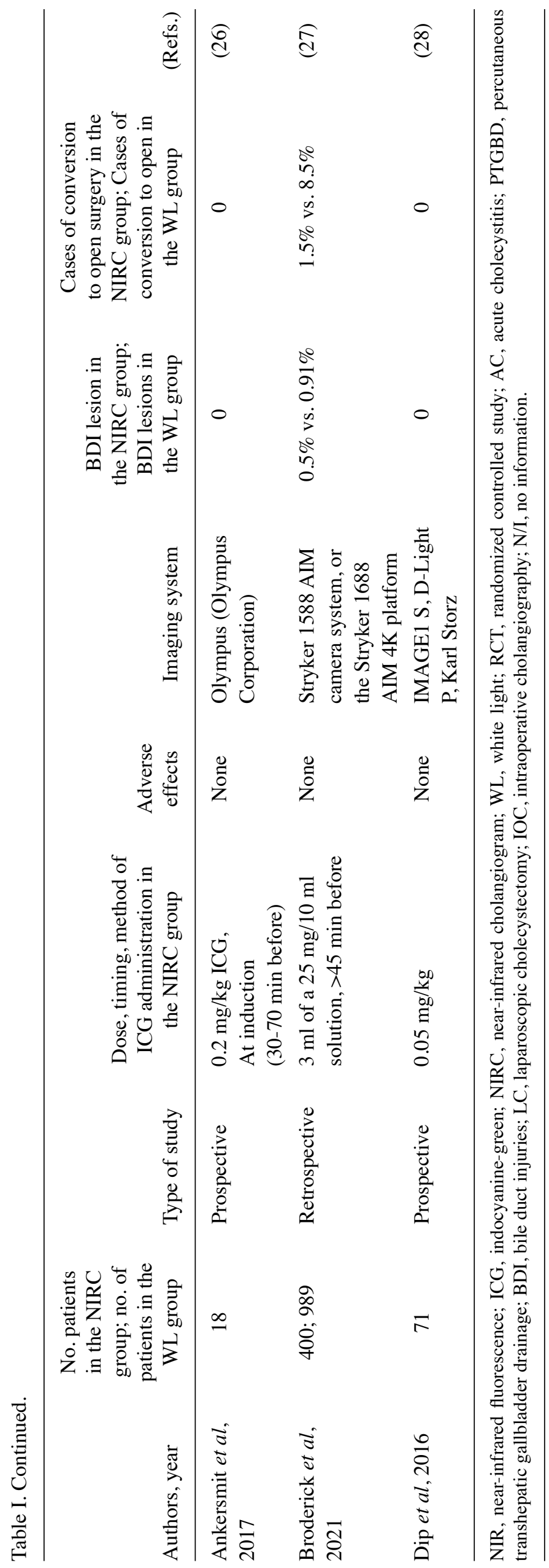


Table II. Visualization of extrahepatic biliary structures with NIRC.

\begin{tabular}{|c|c|c|c|c|c|c|c|}
\hline \multirow[b]{2}{*}{ First author, year } & \multicolumn{3}{|c|}{ Before dissection of Calot's triangle } & \multicolumn{3}{|c|}{ After dissection of Calot's triangle } & \multirow[b]{2}{*}{ (Refs.) } \\
\hline & $\mathrm{CD}(\%)$ & $\mathrm{CBD}(\%)$ & $\mathrm{CHD}(\%)$ & $\mathrm{CD}(\%)$ & CBD $(\%)$ & CHD (\%) & \\
\hline Dip et al, 2019 & $\begin{array}{l}66.6(\mathrm{ICG}) \\
36.2(\mathrm{WL})\end{array}$ & $\begin{array}{l}49.4(\mathrm{ICG}) \\
20.6(\mathrm{WL})\end{array}$ & $\begin{array}{c}28.9(\mathrm{ICG}) \\
10.9(\mathrm{WL})\end{array}$ & $\begin{array}{l}96.9(\mathrm{ICG}) \\
97.2(\mathrm{WL})\end{array}$ & $\begin{array}{c}75.7(\mathrm{ICG}) \\
50(\mathrm{WL})\end{array}$ & $\begin{array}{l}52.3(\mathrm{ICG}) \\
30.5(\mathrm{WL})\end{array}$ & $(11)$ \\
\hline Agnus et al, 2020 & 88.2 & 76.4 & 59.3 & 97.1 & 86.6 & 69.3 & $(12)$ \\
\hline Liu et al, 2018 & $\begin{array}{c}32(\mathrm{ICG}) \\
8(\mathrm{WL})\end{array}$ & $\begin{array}{l}52(\mathrm{ICG}) \\
24(\mathrm{WL})\end{array}$ & $\begin{array}{l}44(\mathrm{ICG}) \\
16(\mathrm{WL})\end{array}$ & $\begin{array}{l}84(\mathrm{ICG}) \\
44(\mathrm{WL})\end{array}$ & $\begin{array}{l}76(\mathrm{ICG}) \\
28(\mathrm{WL})\end{array}$ & $\begin{array}{l}68(\mathrm{ICG}) \\
16(\mathrm{WL})\end{array}$ & (13) \\
\hline Bleszynski et al, 2020 & 90 & 84.3 & 48.1 & $\mathrm{~N} / \mathrm{I}$ & $\mathrm{N} / \mathrm{I}$ & $\mathrm{N} / \mathrm{I}$ & (7) \\
\hline Daskalaki et al, 2014 & 97.8 & 96.1 & 94 & $\mathrm{~N} / \mathrm{I}$ & $\mathrm{N} / \mathrm{I}$ & $\mathrm{N} / \mathrm{I}$ & (14) \\
\hline Buchs et al, 2012 & 91.7 & 50 & 33.3 & 100 & 83.3 & 66.7 & $(15)$ \\
\hline Wang et al, 2020 & $\begin{array}{l}91 \text { (vs. } 74 \\
\text { non ICG) }\end{array}$ & $\begin{array}{l}53 \text { (vs. } 21 \\
\text { non ICG) }\end{array}$ & $\begin{array}{l}79 \text { (vs. } 47 \\
\text { non ICG) }\end{array}$ & $\mathrm{N} / \mathrm{I}$ & $\mathrm{N} / \mathrm{I}$ & $\mathrm{N} / \mathrm{I}$ & (16) \\
\hline Spinoglio et al, 2013 & 93 & 91 & 88 & 97 & 97 & 97 & (22) \\
\hline Ankersmit et al, 2017 & $\begin{array}{l}30.7 \text { (vs. } 16.6 \\
\text { in WL) }\end{array}$ & $\begin{array}{l}15.3 \text { (vs. } 0 \\
\text { in WL) }\end{array}$ & $\mathrm{N} / \mathrm{I}$ & $\begin{array}{c}72 \text { (vs. } 100 \\
\text { WL) }\end{array}$ & $\begin{array}{l}38.8 \text { (vs. } 16.6 \\
\text { in WL) }\end{array}$ & $\mathrm{N} / \mathrm{I}$ & (26) \\
\hline Dip et al, 2016 & $\begin{array}{c}100(\mathrm{BMI} \\
\left.<30 \mathrm{~kg} / \mathrm{m}^{2}\right) \\
100(\mathrm{BMI} \\
\left.>30 \mathrm{~kg} / \mathrm{m}^{2}\right)\end{array}$ & $\begin{array}{c}93.9(\mathrm{BMI} \\
\left.<30 \mathrm{~kg} / \mathrm{m}^{2}\right) \\
81.6(\mathrm{BMI} \\
\left.>30 \mathrm{~kg} / \mathrm{m}^{2}\right)\end{array}$ & $\begin{array}{c}81.8(\mathrm{BMI} \\
\left.<30 \mathrm{~kg} / \mathrm{m}^{2}\right) \\
60.5(\mathrm{BMI} \\
\left.>30 \mathrm{~kg} / \mathrm{m}^{2}\right)\end{array}$ & $\mathrm{N} / \mathrm{I}$ & $\mathrm{N} / \mathrm{I}$ & $\mathrm{N} / \mathrm{I}$ & (28) \\
\hline
\end{tabular}

NIRC, near-infrared cholangiogram; CD, cystic duct; CBD, common bile duct; CHD, common hepatic duct; ICG, indocyanine-green; WL, white light; N/I, no information.

of the cystic and right hepatic arteries, if necessary. In the studies using this timing of administration of ICG, the main drawback was related to the hyperfluorescence of the liver in the background.

Other authors attempted to describe an optimal administration to reduce the fluorescence ratio, by comparing early with delayed administration. Boogerd et al (29) revealed that the highest bile duct-to-liver ratio was achieved 3 to $7 \mathrm{~h}$ after administration of $5 \mathrm{mg}$ and 5-25 h after administration of $10 \mathrm{mg}$ ICG, and recommended administering $5 \mathrm{mg}$ ICG at least $3 \mathrm{~h}$ before imaging. Similar conclusions were revealed by Matsumura et al (18) and Chen et al (30), when comparing early to delayed administration of ICG. The drawbacks of delayed administration are the relative difficulty of using it in emergency or day care surgery.

\section{Factors influencing the intensity of the fluorescence signal and visibility of the extrahepatic biliary structures}

The intensity of the NIRC fluorescence signal was revealed to depend on several factors, including the device used, the distance from the tip of the laparoscope to its target and the amount of covering tissue. It is also important to set the tip of the $0^{\circ}$ or $30^{\circ}$ laparoscope vertically to Calot's triangle to directly irradiate exciting light on the bile ducts and efficiently obtain fluorescence signals (31). A disadvantage of NIRC is that its tissue penetration ability is limited to $5-10 \mathrm{~mm}(16,17)$. The major limitation of an ICG cholangiogram is that it may fail to delineate the deeply located bile ducts during LC (31). This finding explains the lower visualization rate for the common hepatic duct (CHD) in comparison to the more superficial located $\mathrm{CD}$ and the common bile duct (CBD), identified by several authors, and presented in Table II.

The light emitted may not penetrate through the tissues of patients with thick peritoneal fat or patients with peritoneal scarring secondary to inflammation. Thus, in patients with severe cholecystitis and/or obesity, ICG near-infrared fluorescent cholangiography may fail to reveal the whole anatomy of the extrahepatic bile ducts buried in thick connective tissues prior to dissection of Calot's triangle. Wang et al (16) revealed that a BMI $>25 \mathrm{~kg} / \mathrm{m}^{2}$ reduced the visibility of biliary structures in NIRC. Similar results were observed by Dip et al (28), but the decrease met statistical significance only for the most profound structure, the CHD. However, the method remains a helpful tool in comparison to white light only, during dissection, avoiding BDI and bile leakage from the bile duct stump $(16,30,31)$. The smallest rate of visualization of the biliary anatomy prior to Calot's triangle dissection was encountered by Ankersmit et al (26), and this rate could be explained by the fact that the authors included only patients with complicated cholecystitis in the study group, with increased risk of BDI.

\section{ICG NIRC and the rate of BDI and conversion in the study groups}

In the reviewed studies, the incidence of conversion to open surgery varied widely between 0 and $6.25 \%$ in the ICG groups and 0 to $24.69 \%$ in the non-ICG groups, and the higher rates were associated with acute inflammation and complicated 
cholecystitis. Overall, the conversion rate was of $0.52 \%$ in the 2,490 patients in the IGC group and $2.52 \%$ in the patients who underwent LC without ICG NIRC.

The incidence of BDI was $0.12 \%$ in the ICG group (with variations between 0 and $0.5 \%$ ) and $1.31 \%$ in the non-ICG patients, varying from 0 to $4.5 \%$. Studies with a low number of patients and elective surgeries reported similar incidence of complications $(16,17,24)$. Wang et al and Koong et al $(16,17)$ observed no significant decrease in the time necessary to achieve CVS during dissection and blood loss.

Yoshiya et al (19) revealed that the ICG group had a significantly shorter operative time $(129 \pm 46$ vs. $150 \pm 56 \mathrm{~min}$; $\mathrm{P}=0.0455)$, markedly lower conversion rate (2.6 vs. $22.0 \%$; $\mathrm{P}=0.0017)$, and lower proportion of subtotal cholecystectomy ( 0 vs. $6.6 \% ; \mathrm{P}=0.0359)$ than the non-ICG group. Similar results were revealed by Sharma et al (20) and Gangemi et al (21), when comparing RC with ICG and LC. The evidence supports the theory that fluorescent cholangiography during $\mathrm{RC}$ may contribute to proper identification of biliary structures and may reduce the rates of open conversion. However, the authors admit that there was an increased percentage of AC in the LC group. It is debatable whether the results were consequences of an improved visualization of the ICG dye or it may be a result of the increased visualization and ergonomics of the robotic platform. At this stage of development, the literature on intraoperative ICG in LC focused primarily on the efficacy of technology and its ability to identify structures and less on clinical outcomes, while a direct comparison of ICG-aided RC and LC was not performed (21).

Broderick et al (27) revealed that overall BDI were decreased with the use of an ICG cholangiogram, suggesting that improved visualization of the biliary tree via ICG as standard of care during LC may decrease the rate of iatrogenic injury.

\section{Challenges in laparoscopic cholecystectomy using ICG NIR}

Optimal gallbladder dissection requires direct visualization in order to obtain the CVS and reduce the risk of BDI. ICG cholangiography is unable to completely replace direct visualization; however, it provides an alternative perspective in identifying Calot's triangle. This enhanced biliary visualization with ICG could provide comfort for the operating surgeon, in that the $\mathrm{CD}, \mathrm{CBD}$, and CHD have been properly identified prior to clipping of the CD and cystic artery (7). With the development of the imaging systems and software of the most used devices for laparoscopy, NIR ICG cholangiography is becoming more readily available to the surgeon, in every day practice. This may be an option for increased safety of new surgeons, that are learning the $\mathrm{LC}$ technique. In addition, it may improve the early cholecystectomy rates in $\mathrm{AC}$ and decrease the rate of $\mathrm{BDI}$ and conversion in complicated cases.

Drawbacks of NIRF-C lie in the need to inject a fluorophore, the inability to detect retained stones, and the noise fluorescence signal from the liver. In a comparative study, the relatively high fluorescence liver background led surgeons to assign a lower score to the image quality obtained with NIRF-C, when compared with X-ray intraoperative cholangiography (32). Conversely, in a systematic review by
Vlek et al (33), the results revealed similar results for biliary tract visualization with near-infrared imaging with ICG during LC compared with conventional intraoperative cholangiography, but more standardization and optimization are needed in the ICG technique. To enhance the contrast between the fluorescence of the extrahepatic biliary ducts and the liver in the background, various strategies have been employed including delayed intravenous administration (3-24 h prior to surgery), or, alternatively administration of ICG directly into the gallbladder, either by a preplaced drain tube or by direct intraoperative cystic injection. In the second case, there is some risk of dye spillage, which could impair the visibility by contaminating the operative field (13). The dose is smaller, and the technique has been applied in $\mathrm{AC}$, after puncture, when the local inflammation decreases the visibility of the CVS. CD permeability is essential to obtain the image of the CBD and the intraoperative injection requires LC suturing skills, to create the sealing pouch at the level of the gallbladder, which is also a time-consuming step.

There was an increased variability in dose and timing of the ICG administration reported in the studies included in the present review, rendering a meta-analysis unreliable due to increased risk of bias. Further standardization and training in this technique are necessary for a comprehensive approach, but differences in fluorescence imaging systems also hinder comparisons between fluorescence cholangiography studies (29). In a previous study by Kono et al (31), 5 different fluorescence laparoscopic imaging systems for fluorescence cholangiography were compared including a prototype and an improved version of the Hamamatsu Photonics laparoscope, the fluorescence imaging system of Olympus Medical Systems, the Karl Storz HD fluorescence laparoscope, and the fluorescence imaging system of Novadaq. The results indicated that the contrast of ICG was significantly different among all the used laparoscopic imaging systems, which makes the outcomes difficult to compare.

The European registry on fluorescence image-guided surgery (FIGS) (www.euro-figs.eu) aims to obtain a snapshot of the current practices of FIGS and is a valuable tool in promoting and monitoring FIGS-related educational and consensus activities in Europe (12).

As both BDI and conversion are low-frequency complications of LC, the differences between the ICG group and the non-ICG group become statistically significant with a high number of patients. In smaller groups, these complications may not be encountered naturally, or vice versa, the presence of 1-2 separate cases may significantly increase the incidence rate. Although certain authors, such as Koong et al (17) did not reveal a statistical advantage in the use of ICG near-infrared fluorescent cholangiography for establishing CVS, they did demonstrate that an ICG NIR cholangiogram was safe and clinically not inferior. Moreover, it may be a helpful tool for residents or new surgeons, on the learning curve of LC (17).

In a systematic review and meta-analysis performed by Liu et al (34), including 11 studies, with a total of 2,221 patients, the ICG group was revealed to benefit from statistically significant shorter operative time, shorter biliary anatomy identification time, lower blood loss, higher success rate of biliary tract imaging, lower rate of conversion to open surgery and shorter hospital stay (34). 
In a review performed by Pesce et al (35), the frequencies of detection of the extrahepatic biliary system ranged from 71.4 to $100 \%$ for the CD, 33.3 to $100 \%$ for the CHD, 50 to $100 \%$ for the CBD, and 25 to $100 \%$ for the CD-CHD junction, with a significant decreased rate of visualization in patients with a BMI $>35 \mathrm{~kg} / \mathrm{m}^{2}$. In the present review, a significant lower rate of visualization of extrahepatic biliary structures was revealed in only one study (26), in which ICG was employed for numerous patients with complicated cholecystitis, when compared with that reported by Pesce et al (35). Although in patients with a higher BMI and/or cholecystitis, fluorescence intensity is lower, NIRF appears to be particularly more helpful (36) in performing a safe dissection and reaching CVS.

\section{Conclusions}

In conclusion, ICG NIRC is considered a promising tool to increase safety in LC. Its use in combination with white light has been demonstrated to be superior to white light alone in identifying the extrahepatic biliary anatomy, thus decreasing the risk of intraoperative BDI. The intensity of the NIRC fluorescence signal was revealed to depend on several factors, with obesity and inflammation as the most clinically significant. Large-scale use of ICG NIRC is necessary in order to obtain data to confirm its clinical value and specific indications.

\section{Acknowledgements}

Not applicable.

\section{Funding}

No funding was received.

\section{Availability of data and materials}

All data generated or analyzed during this study are included in this published article.

\section{Authors' contributions}

DCB, DS, AMD, DD, CTu and BS conceived and designed the study. CGS, CTa, ADS, AZ, LCT, AMD, SAB, ACC, DOC and $\mathrm{BS}$ performed the data collection and analysis. DS, DCB, CGS, CTa and MST drafted the manuscript. DS, MST, CGS, SAB, CTu, DD, AZ, ACC, DOC and ADS revised the study from a critical perspective for important intellectual content. DS, LCT and AMD confirm the authenticity of the raw data. The final version of the manuscript was read and approved by all authors.

\section{Ethics approval and consent to participate}

Not applicable.

\section{Patient consent for publication}

Not applicable.

\section{Competing interests}

The authors declare that they have no competing interests.

\section{References}

1. Gupta V and Jain G: Safe laparoscopic cholecystectomy: Adoption of universal culture of safety in cholecystectomy. World J Gastrointest Surg 11: 62-84, 2019.

2. van de Graaf FW, Zaïmi I, Stassen LPS and Lange JF: Safe laparoscopic cholecystectomy: A systematic review of bile duct injury prevention. Int J Surg 60: 164-172, 2018.

3. Conrad C, Wakabayashi G, Asbun HJ, Dallemagne B, Demartines N, Diana M, Fuks D, Giménez ME, Goumard C, Kaneko H, et al: IRCAD recommendation on safe laparoscopic cholecystectomy. J Hepatobiliary Pancreat Sci 24: 603-615, 2017.

4. Serban D, Socea B, Balasescu SA, Badiu CD, Tudor C, Dascalu AM, Vancea G, Spataru RI, Sabau AD, Sabau D and Tanasescu C: Safety of laparoscopic cholecystectomy for acute cholecystitis in the elderly: A multivariate analysis of risk factors for intra and postoperative complications. Medicina (Kaunas) 57: 230,2021

5. Fometescu SG, Costache M, Coveney A, Oprescu SM, Serban D and Savlovschi C: Peritoneal fibrinolytic activity and adhesiogenesis. Chirurgia (Bucur) 108: 331-340, 2013.

6. Song GM, Bian W, Zeng XT, Zhou JG, Luo YQ and Tian X: Laparoscopic cholecystectomy for acute cholecystitis: Early or delayed?: Evidence from a systematic review of discordant meta-analyses. Medicine (Baltimore) 95: e3835, 2016.

7. Bleszynski MS, DeGirolamo KM, Meneghetti AT, Chiu CJ and Panton ON: Fluorescent cholangiography in laparoscopic cholecystectomy: An updated canadian experience. Surg Innov 27: 38-43, 2020.

8. Ishizawa T, Tamura S, Masuda K, Aoki T, Hasegawa K, Imamura H, Beck Y and Kokudo N: Intraoperative fluorescent cholangiography using indocyanine green: A biliary road map for safe surgery. J Am Coll Surg 208: e1-e4, 2009.

9. Dip F, Lo Menzo E, White KP and Rosenthal RJ: Does near-infrared fluorescent cholangiography with indocyanine green reduce bile duct injuries and conversions to open surgery during laparoscopic or robotic cholecystectomy? -A meta-analysis. Surgery 169: 859-867, 2021.

10. van Manen L, Handgraaf HJM, Diana M, Dijkstra J, Ishizawa T, Vahrmeijer AL and Mieog JSD: A practical guide for the use of indocyanine green and methylene blue in fluorescence-guided abdominal surgery. J Surg Oncol 118: 283-300, 2018.

11. Dip F, LoMenzo E, Sarotto L, Phillips E, Todeschini H, Nahmod M, Alle L, Schneider S, Kaja L, Boni L, et al: Randomized trial of near-infrared incisionless fluorescent cholangiography. Ann Surg 270: 992-999, 2019.

12. Agnus V, Pesce A, Boni L, Van Den Bos J, Morales-Conde S, Paganini AM, Quaresima S, Balla A, La Greca G, Plaudis H, et al: Fluorescence-based cholangiography: Preliminary results from the IHU-IRCAD-EAES EURO-FIGS registry. Surg Endosc 34: 3888-3896, 2020.

13. Liu YY, Liao CH, Diana M, Wang SY, Kong SH, Yeh CN, Dallemagne B, Marescaux J and Yeh TS: Near-infrared cholecystocholangiography with direct intragallbladder indocyanine green injection: Preliminary clinical results. Surg Endosc 32: 1506-1514, 2018.

14. Daskalaki D, Fernandes E, Wang X, Bianco FM, Elli EF, Ayloo S, Masrur M, Milone L and Giulianotti PC: Indocyanine green (ICG) fluorescent cholangiography during robotic cholecystectomy: Results of 184 consecutive cases in a single institution. Surg Innov 21: 615-621, 2014.

15. Buchs NC, Hagen ME, Pugin F, Volonte F, Bucher P, Schiffer E and Morel P: Intra-operative fluorescent cholangiography using indocyanin green during robotic single site cholecystectomy. Int J Med Robot 8: 436-440, 2012.

16. Wang C, Peng W, Yang J, Li Y, Yang J, Hu X, Xia L, Zhang L, Zhong Y, Qiao L and Pan W: Application of near-infrared fluorescent cholangiography using indocyanine green in laparoscopic cholecystectomy. J Int Med Res 48: 300060520979224, 2020

17. Koong JK, Ng GH, Ramayah K, Koh PS and Yoong BK: Early identification of the critical view of safety in laparoscopic cholecystectomy using indocyanine green fluorescence cholangiography: A randomised controlled study. Asian J Surg 44: 537-543, 2021. 
18. Matsumura M, Kawaguchi Y, Kobayashi Y, Kobayashi K, Ishizawa T, Akamatsu N, Kaneko J, Arita J, Kokudo N and Hasegawa K: Indocyanine green administration a day before surgery may increase bile duct detectability on fluorescence cholangiography during laparoscopic cholecystectomy. J Hepatobiliary Pancreat Sci 28: 202-210, 2021.

19. Yoshiya S, Minagawa R, Kamo K, Kasai M, Taketani K, Yukaya T, Kimura Y, Koga T, Kai M, Kajiyama K and Yoshizumi T: Usability of intraoperative fluorescence imaging with indocyanine green during laparoscopic cholecystectomy after percutaneous transhepatic gallbladder drainage. World J Surg 43: 127-133, 2019.

20. Sharma S, Huang R, Hui S, Smith MC, Chung PJ, Schwartzman A and Sugiyama G: The utilization of fluorescent cholangiography during robotic cholecystectomy at an inner-city academic medical center. J Robot Surg 12: 481-485, 2018.

21. Gangemi A, Danilkowicz R, Elli FE, Bianco F, Masrur M and Giulianotti PC: Could ICG-aided robotic cholecystectomy reduce the rate of open conversion reported with laparoscopic approach? A head to head comparison of the largest single institution studies. J Robot Surg 11: 77-82, 2017.

22. Spinoglio G, Priora F, Bianchi PP, Lucido FS, Licciardello A, Maglione V, Grosso F, Quarati R, Ravazzoni F and Lenti LM: Real-time near-infrared (NIR) fluorescent cholangiography in single-site robotic cholecystectomy (SSRC): A single-institutional prospective study. Surg Endosc 27: 2156-2162, 2013.

23. Osayi SN, Wendling MR, Drosdeck JM, Chaudhry UI Perry KA, Noria SF, Mikami DJ, Needleman BJ, Muscarella P II, Abdel-Rasoul M, et al: Near-infrared fluorescent cholangiography facilitates identification of biliary anatomy during laparoscopic cholecystectomy. Surg Endosc 29: 368-375, 2015.

24. Ambe PC, Plambeck J, Fernandez-Jesberg V and Zarras K: The role of indocyanine green fluoroscopy for intraoperative bile duct visualization during laparoscopic cholecystectomy: An observational cohort study in 70 patients. Patient Safe Surg 13: 2, 2019.

25. Quaresima S, Balla A, Palmieri L, Seitaj A, Fingerhut A, Ursi P and Paganini AM: Routine near infra-red indocyanine green fluorescent cholangiography versus intraoperative cholangiography during laparoscopic cholecystectomy: A case-matched comparison. Surg Endosc 34: 1959-1967, 2020.

26. Ankersmit M, van Dam DA, van Rijswijk AS, van den Heuvel B, Tuynman JB and Meijerink WJHJ: Fluorescent imaging with indocyanine green during laparoscopic cholecystectomy in patients at increased risk of bile duct injury. Surg Innov 24: $245-252,2017$
27. Broderick RC, Lee AM, Cheverie JN, Zhao B, Blitzer RR, Patel RJ, Soltero S, Sandler BJ, Jacobsen GR, Doucet JJ and Horgan S: Fluorescent cholangiography significantly improves patient outcomes for laparoscopic cholecystectomy. Surg Endosc 35: 5729-5739, 2021.

28. Dip F, Nguyen D, Montorfano L, Szretter Noste ME, Lo Menzo E, Simpfendorfer C, Szomstein S and Rosenthal R: Accuracy of near infrared-guided surgery in morbidly obese subjects undergoing laparoscopic cholecystectomy. Obes Surg 26: 525-530, 2016.

29. Boogerd LSF, Handgraaf HJM, Huurman VAL, Lam HD Mieog JSD, van der Made WJ, van de Velde CJH and Vahrmeijer AL: The best approach for laparoscopic fluorescence cholangiography: Overview of the literature and optimization of dose and dosing time. Surg Innov 24: 386-396, 2017.

30. Chen Q, Zhou R, Weng J, Lai Y, Liu H, Kuang J, Zhang S, Wu Z, Wang $\mathrm{W}$ and $\mathrm{Gu} \mathrm{W}$ : Extrahepatic biliary tract visualization using near-infrared fluorescence imaging with indocyanine green: Optimization of dose and dosing time. Surg Endosc 35: 5573-5582, 2021

31. Kono Y, Ishizawa T, Tani K, Harada N, Kaneko J, Saiura A, Bandai Y and Kokudo N: Techniques of fluorescence cholangiography during laparoscopic cholecystectomy for better delineation of the bile duct anatomy. Medicine (Baltimore) 94: e1005, 2015.

32. Diana M, Soler L, Agnus V, D'Urso A, Vix M, Dallemagne B, Faucher V, Roy C, Mutter D, Marescaux J and Pessaux P: Prospective evaluation of precision multimodal gallbladder surgery navigation: Virtual reality, near-infrared fluorescence, and X-ray-based intraoperative cholangiography. Ann Surg 266: 890-897, 2017.

33. Vlek SL, van Dam DA, Rubinstein SM, de Lange-de Klerk ESM, Schoonmade LJ, Tuynman JB, Meijerink WJHJ and Ankersmit M: Biliary tract visualization using near-infrared imaging with indocyanine green during laparoscopic cholecystectomy: Results of a systematic review. Surg Endosc 31: 2731-2742, 2017.

34. Liu Y, Peng Y, Su S, Fang C, Qin S, Wang X, Xia X, Li B and He P: A meta-analysis of indocyanine green fluorescence image-guided laparoscopic cholecystectomy for benign gallbladder disease. Photodiagnosis Photodyn Ther 32: 101948, 2020.

35. Pesce A, Piccolo G, La Greca G and Puleo S: Utility of fluorescent cholangiography during laparoscopic cholecystectomy: A systematic review. World J Gastroenterol 21: 7877-7883, 2015.

36. van den Bos J, Wieringa FP, Bouvy ND and Stassen LPS: Optimizing the image of fluorescence cholangiography using ICG: a systematic review and ex vivo experiments. Surg Endosc 32: 4820-4832, 2018 